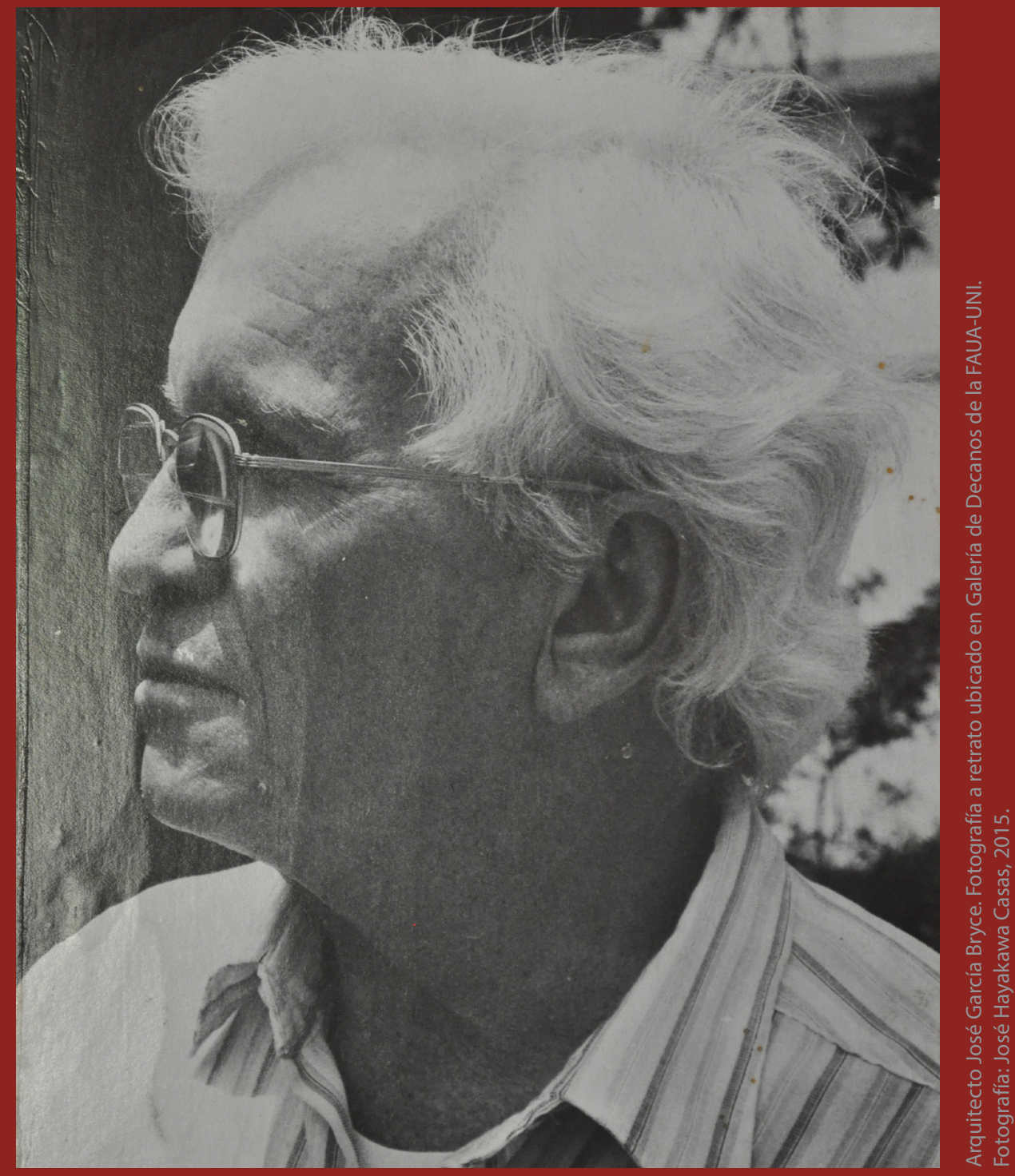

\title{
Entrevista José García Bryce
}

Nació en Lima en 1928. Estudió en la Escuela de Ingenieros (actual Universidad Nacional de Ingeniería) y se graduó como arquitecto en 1952, y continuó estudios de Posgrado en la Universidad de Roma (1952-1953). Luego estudiaría Historia del Arte en la Universidad de París La Sorbona y en la Universidad de Múnich de 1953 a 1955. En 1964, obtuvo el grado de magíster en Historia del Arte de la Universidad de Harvard. Estudió Historia del Arte en Italia, Francia y España. Posee un grado de magíster en la misma disciplina realizado en la Universidad de Harvard en 1964. En el ámbito internacional fue profesor en la Universidad de Yale sobre arquitectura latinoamericana del siglo XIX y en el Perú se desempeñó como profesor de la Universidad Nacional de Ingeniería entre 1951 y 1991, de la Universidad Ricardo Palma entre 1997 y 2006, y actualmente es profesor de la UPC. El arquitecto García Bryce ha ganado notables reconocimientos debido a su gran labor académica y profesional, como el premio Chavín al fomento de la cultura (1963); el premio Bolivariano (1965); el Hexágono de Oro en 1981, en virtud a la construcción de la Capilla San José (distrito de La Victoria-Lima); y el Cubo de Acero en la Bienal de Buenos Aires en 1986. En 1992 fue nombrado profesor benemérito por la Universidad Nacional de Ingeniería. Ha participado en la célebre Junta Deliberante Metropolitana de Monumentos Históricos, Artísticos y Lugares Arqueológicos de Lima, así como en diversas restauraciones y comisiones de patrimonio arquitectónico llevados a cabo por el Colegio de Arquitectos del Perú y el Instituto Nacional de Cultura. 
devenir Vol. 2, Nº4, JULIO - DICIEMBRE 2015, PP. 179-183 - ENTREVISTA | ISSN 2312-7570

UNIVERSIDAD NACIONAL DE INGENIERÍA, LIMA

Entrevistamos al arquitecto José García Bryce en relación a la investigación titulada 1964-2004: La formación en restauración de monumentos arquitectónicos en la Universidad Nacional de Ingeniería, desarrollada por el equipo de investigación conformado por el Arq. José Correa Orbegoso, el MSc. Arq. José Hayakawa Casas y la Srta. María Copaira Ortiz, con el auspicio del Instituto de Investigaciones de la Facultad de Arquitectura, Artes y Urbanismo de la Universidad Nacional de Ingeniería en el marco conmemorativo de los 100 años de enseñanza de formación profesional de los arquitectos en el Perú, especialmente en lo que respecta al tema del patrimonio construido'.

JC: A pesar de que nuestro proyecto de investigación emprendido en la UNI con la participación de José Hayakawa y María Copaira, que toma como cota histórica inicial al año 1964, queríamos saber si en la época en que tú estudiaste -en la Escuela de Ingenieros, luego Facultad de Arquitectura- se trataba el tema de la conservación del patrimonio edificado. ¿Había interés en la restauración de monumentos? ¿Había un curso específico y especializado sobre este tema?

JG: No, no hubo. No sé cuándo se comenzaron a dar los primeros pasos para incorporar un curso de restauración de monumentos, pero definitivamente no existía un curso de restauración cuando yo estudié... Cuando yo ingresé no había un curso de ese tipo ni había tampoco conciencia respecto al tema patrimonial. Ya se había creado el Consejo Nacional de Conservación y Restauración de Monumentos Históricos y Artísticos, que era una cosa interesante y valiosa formada por un grupo de gente mayor, pero a nivel de los estudiantes y de los profesores de la Escuela de Ingenieros de aquella época no había esa preocupación ni interés generalizado. Tampoco existía como tema la historia de la arquitectura o los estudios de la arquitectura del Perú. La única historia que se impartía era historia del arte, la cual cuando yo estudié era ya específicamente de la arquitectura. Además, había arte también, pero era arte universal: Egipto, Mesopotamia, Grecia, Roma, etc., y no había arquitectura peruana.

Tampoco había historia de la cultura peruana, aunque esto lo sé a través de El Arquitecto Peruano y documentos anteriores a mí. Sé que hubo interés por la arquitectura colonial de parte de Rafael Marquina en la entonces Sección de Arquitectura... Eso debe haber sido hacia fines de los años 30. Las actividades consistían en visitar algunos edificios antiguos de Lima, por ejemplo San Francisco, y hacer apuntes sobre la arquitectura peruana del Virreinato. Mucho después de eso se gestó el estudio de la peruana. En esa línea, me parece, un primer episodio viene a ser la presencia del arqueólogo Muelle, el arqueólogo que fue llevado por Belaúnde.

\section{JC: ¿El Dr. Jorge C. Muelle?}

Sí. Él fue quien comenzó a enseñar arqueología, lo prehispánico. Después apareció el curso Arquitectura Peruana... Me parece que otros cursos de arquitectura peruana fueron creados formalmente en la UNI en la época de las unidades institucionales denominadas 'departamentos', cuando se 'departamentalizó' la UNI. En la época del Gobierno Nacional en manos del Gral. Juan Velasco es que se crea un curso de Arquitectura Peruana en lo que era ya la Facultad de Arquitectura de la UNI, me parece...

Como explicaba, en los años 50 debe haber sido ese el escenario. En este contexto, es que me encargan -en colaboración con otros profesores más- montar esta asignatura. Desarrollamos algunas entrevistas a posibles profesores para el curso y uno de los candidatos era nada menos que el arquitecto Emilio Harth-Terré. Así fue que ingresó a enseñar Harth-Terré en la Facultad de Arquitectura de la UNI, en un curso sobre arquitectura peruana, el cual abordaba fundamentalmente la arquitectura de la Colonia. La temática de la restauración ya vendría después, me parece...

JC: ¿En los cursos de Arquitectura Peruana que tú tenías a cargo y en otros se despertaba el interés de los alumnos a partir de algún trabajo práctico de conservación de tal o cual

1. Entrevista realizada el 6 de octubre de 2010, por el Arq. José Correa y la Srta. María Copaira 
edificio, tal vez incitándolos a percatarse que se trataba de un patrimonio que ya estaba en peligro en ese momento debido a los ensanches urbanos y una serie de obras'modernizadoras'?

En esos años ya se había perdido una considerable cantidad de patrimonio edificado. Me parece que primero solo tuvo lugar lo que tú llamas formación académica, es decir, la exposición de las obras sin enfocarla hacia el problema de la restauración monumental.

JC: Harth-Terré ya era profesor de la UNI, ¿no?

¿Tú lo tuviste de profesor? Yo asistía también. Yo era ya profesor de la UNI, por supuesto, pero asistía también a sus clases.

JC: Él era muy entusiasta. Si hablaba de la Fortaleza de Paramonga, por ejemplo, decía “...yo la he restaurado, porque yo fui y me trepé... hice esto y el otro...". Mostraba esa veta de la especialidad que no solo era la historia académica, sino la posibilidad de trabajar...

De intervenir, de consolidar.

JC: En el caso de la portada de La Merced, él la defendía con gran pasión y convicción frente a las críticas que ya se le habían hecho en algún momento. Eso contribuyó también a despertar el interés por ese tema...

Por ese tema, por esa veta, por esa área de trabajo...

JC: Aparte de lo que ya había publicado, también había trabajado muchísimo después del terremoto de 1940.

Sí, él intervino, en La Merced. Fue una de las obras de restauración monumental donde más intervino Harth-Terré, además de en la Basílica Catedral de Lima. En los campanarios y las torres de la catedral.

\section{JC: Y en la torre de Santo Domingo...}

En la torre de Santo Domingo también, efectivamente, y seguramente en muchas otras cosas que no sabría precisar bien cuáles y cuántas eran... En la Iglesia de La Merced reconstruyó íntegramente la Portada de Los Guitarreros, una portada lateral, de acuerdo a su conocida tesis, según la cual había que reemplazar los materiales un poco débiles de la arquitectura de Lima -sobre todo la parte de quincha, de madera y quincha- por concreto... por cemento.

\section{JC: Por "material noble".}

Por el nuevo material durable, más durable.

\section{JC: Acerca del convenio con la Fundación Ford, ¿tú fuiste codirector del proyecto?}

Yo intervine ahí. Sí.

JC: ¿Fue una época y un proyecto muy importante, no?

Muy importante, tanto que hasta hora es de utilidad. Sin embargo, creo que mi intervención no fue muy importante ni protagónica. Se me borra de la memoria concretamente qué dimensión y alcance tuvo, cómo fue mi vinculación con el proyecto de la Fundación Ford, pero sí recuerdo haber tenido intervención en este gran proyecto. No sé si para el registro o la aprobación de un registro de las obras; posiblemente fue para eso.

JC: Para inventariar, fichar...

Bueno, dentro de esa línea un trabajo que fue importante -pero por supuesto no tiene relación con la universidad, con la Facultad de Arquitectura de la UNI- es el valioso trabajo realizado a ini- 
devenir Vol. 2, Nº, JULIO - DICIEMBRE 2015, PP. 179-183 - ENTREVISTA | ISSN 2312-7570

UNIVERSIDAD NACIONAL DE INGENIERÍA, LIMA

cios de la década del 60 por la Junta Deliberante Metropolitana de Monumentos Históricos, Artísticos y Lugares Arqueológicos de Lima, donde se produjeron los primeros planos monumentales que se hicieron de Lima Metropolitana, que incluían no solo el Centro Histórico de Lima sino los de otros distritos históricos. Por ejemplo, Barranco, Chorrillos... Y también tenía un listado de monumentos, de clasificaciones...

\section{JC: Hasta la 'doble intangibilidad' famosa}

Sí, el criterio de la 'doble intangibilidad', que fue una idea introducida por nuestro querido colega, el arquitecto Raúl Morey. Él nos ha dejado eso. Él fue uno de los principales propulsores del trabajo al interior de la Junta Deliberante.

JC: ¿De la Junta Deliberante?

Sí, sí. Fue un equipo conformado por mucha gente, de procedencias disciplinares muy diversas. Cubríamos muchas áreas...Estaba el arquitecto Luis Miró Quesada en la parte urbanística. Teníamos historiadores...

JC: Ugarte Eléspuru también...

Claro. Él era el presidente de la Junta Deliberante Metropolitana de Monumentos Históricos, Artísticos y Lugares Arqueológicos de Lima. Estaba también Benites... Era un equipo técnico conformado por profesionales de muchas generaciones, porque incluía a arquitectos como Rafael Marquina, Héctor Velarde, Víctor Pimentel y yo. Es decir, dos grandes maestros y dos novatos, respectivamente...

MC: Arquitecto, sobre el Inventario del Patrimonio Monumental de Lima. Valles del Chillón, Rímac y Lurín, elaborado con la Fundación Ford, ¿exactamente qué es lo que recuerda? ¿Cómo fue el proceso de trabajo y desarrollo?

No recuerdo con precisión, pero supongo que hay documentos de datos preliminares. Recuerdo bien que en su momento histórico fue un esfuerzo monumentalista importante; recuerdo haber tenido frecuentes reuniones de trabajo y coordinación, pero nada más concreto o especifico.

MC: Arquitecto García Bryce, en la época en que usted enseñaba en la Facultad de Arquitectura, Urbanismo y Artes, más o menos, ¿hasta qué año fue docente de la UNI?

Fui docente de Arquitectura en la UNI hasta 1991.

MC: Entonces, cuando ya existía el curso de restauración de monumentos, ¿usted pudo ver algún vínculo entre el curso y el Área Académica de Historia de la Arquitectura? ¿Existió relación con los otros cursos de esa área, o siempre fueron aisladas e inconexas?

Creo que no hubo relación directa. Han sido aisladas e independientes, aunque por supuesto existía siempre la posibilidad de brindar asesoría o la consulta de los alumnos de esta área de restauración con quienes teníamos responsabilidades lectivas en las asignaturas de Historia de la Arquitectura y/o Urbanismo.

MC: Se menciona en nuestra investigación que hubo una época en que el curso de restauración fue obligatorio. ¿Usted recuerda algo sobre eso?

No, no recuerdo con precisión. Es posible que haya sido un curso obligatorio durante una época, pero no lo recuerdo bien. ¿actualmente no es obligatorio?

MC: No, es electivo.

JC: No era obligatorio tampoco cuando yo lo seguí. Era un electivo a cargo del arquitecto Víctor Pimentel. 
Bueno, yo francamente no me puedo fiar de la memoria; no podría asegurar a ciencia cierta si fue obligatorio en sus inicios...

JC: Creo que en los años 80 se volvió obligatorio durante algunos años. Para terminar, quiero que nos refiera a otro producto cultural muy interesante, donde yo personal y profesionalmente me he beneficiado de vuestra labor: el proyecto de restauración monumental para la iglesia de Copacabana en el distrito del Rímac. ¿Ello se hizo como una siguiente etapa o una actividad colateral al trabajo del Inventario del Patrimonio Monumental de Lima. Valles del Chillón, Rímac y Lurín elaborado con la Fundación Ford? Recuerdo que se preparó el proyecto e inclusive decía en la misma documentación "Proyecto dentro del Inventario de la Fundación Ford..."

Sí, esa era la idea central, trabajarlo en ese marco que refieres. Sin embargo, el proyecto de restauración para la iglesia de Copacabana fue, desde sus inicios y en todo su desarrollo, bastante independiente del trabajo base del inventario monumental realizado con la Fundación Ford. Claro que se puede considerar como una especie de proyecto piloto, pero estuvo más vinculado con la gestión e iniciativa del colegio que funciona ahí mismo, un pequeño colegio de niñas y la iglesia de lo que era antiguamente el Monasterio de Copacabana.

JC: El Beaterío de Copacabana...

Allí había una religiosa muy activa, muy emprendedora, con muchísima iniciativa...Yo no sé si vino completamente de ella la iniciativa de dirigirse a la Facultad de Arquitectura de la UNI en la época del decanato FAUA del arquitecto Javier Sota Nadal. Creo que fue así. Entonces se armó ese proyecto...

JC: Claro, el cual yo tuve la oportunidad de aplicar después. Porque el proyecto se hizo antes, ¿no? Recuerdo que hubo un temblor fuerte o algo así de pernicioso, y ello obligó a cerrar la iglesia...

Sí, la iglesia estaba cerrada...

JC: Efectivamente, porque ya la bóveda había estado en situación crítica, y esa misma religiosa fue la que después se empeñó en realizar la obra, ¿no? Y la base fue el proyecto que tú realizaste en la Facultad de Arquitectura de la UNI.

Sí, claro. Así mismo fue...

JC: Gracias reiteradas, gran maestro Arq. José García Bryce, por su tiempo y el interés demostrado en los objetivos de esta investigación... ¡Será hasta la próxima! 